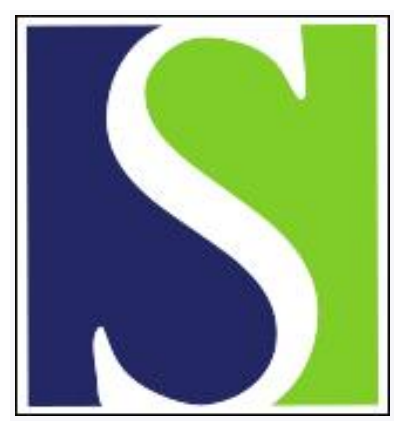

Scand J Work Environ Health 2011;37(5):418-426

https://doi.org/10.5271/sjweh.3162

Published online: 07 Apr 2011, Issue date: Sep 2011

Weekend sleep intervention for workers with habitually short sleep periods

by Kubo T, Takahashi M, Sato T, Sasaki T, Oka T, Iwasaki K

Affiliation: National Institute of Occupational Safety and Health, 6-21-1, Nagao, Tama-ku, Kawasaki 214-8585, Japan. kubo@h.jniosh.go.jp

Refers to the following texts of the Journal: 2006;32(4):318-327

2006;32(6):502-514 2008;34(3):213-223 2003;29(3):171-188

Key terms: alertness; fatigue; performance; short sleep; sleep; sleep debt; sleep intervention; sleepiness; weekend sleep extension

This article in PubMed: www.ncbi.nlm.nih.gov/pubmed/21475780

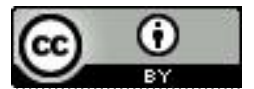




\title{
Weekend sleep intervention for workers with habitually short sleep periods
}

\author{
by Tomohide Kubo, PhD, ${ }^{1}$ Masaya Takahashi, PhD, ${ }^{1}$ Tomoaki Sato, PhD, ${ }^{2}$ Takeshi Sasaki, MSc, ${ }^{1}$ Tatsuo \\ Oka, BA, ${ }^{1}$ Kenji Iwasaki, PhD ${ }^{1}$
}

\begin{abstract}
Kubo T, Takahashi M, Sato T, Sasaki T, Oka T, Iwasaki K. Weekend sleep intervention for workers with habitually short sleep periods. Scand J Work Environ Health 2011;37(5):418-426. doi:10.5271/sjweh.3162

Objective This study was conducted to determine whether extended sleep time during the weekend improves
alertness and performance during the subsequent week for workers who are habitually short on sleep time.

Methods Daytime employees in the manufacturing industry [38.3, standard deviation (SD) 8.1 years old, mean weekday sleep $\leq 6$ hours] participated in a study that lasted 3 successive weeks. Participants were instructed to stay in bed for $\geq 8$ hours between 22:00-09:00 hours on weekends during the first week as a sleep intervention condition and keep their habitual sleep-wake patterns as a habitual weekend sleep condition beginning the weekend of the second week through Thursday of the third week. Half the participants underwent the conditions in one order and the other half in the reverse. Sleep was monitored by an actigraph. A psychomotor vigilance task, subjective fatigue, and blood pressure were measured on Monday and Thursday during the afternoon each week.
\end{abstract}

Results Sleep duration on weekends was approximately 2 hours longer per day during the intervention. However, sleep duration during weekdays following the intervention returned to shorter periods. Significantly shorter reaction times and a smaller number of lapses on the psychomotor vigilance task were found on Mondays after the intervention than after the habitual weekend sleep. The opposite results, however, were observed on Thursdays.

Conclusions Sleep extension on weekends may be effective in improving alertness and performance during the first days in subsequent weeks among workers with short sleep times. These benefits might be maintained if sufficient sleep duration continues.

Key terms alertness; fatigue; performance; sleepiness; sleep debt; weekend sleep extension.

Working overtime is common in developed countries and has increased in recent years (1). Previous studies have suggested an association between long working hours and adverse health outcomes, such as insufficient sleep, depression, and cardiovascular disease (2-4). In particular, a great deal of research has focused on the influence of overtime work on health problems in Japan (5-7).

Sleep plays an essential role in recovery from workrelated fatigue (8). Shortened sleep due to long working hours or overtime may thus increase the likelihood of insufficient recovery from fatigue (9-11) and stressrelated diseases (12-15). Therefore, an intervention to ensure adequate sleep is required to protect workers' health and well-being. A potential opportunity for such an intervention is assumed to be available either during weekdays or on weekends. For example, it may be effective to set a "no-overtime" day in the middle of the week. Alternatively, an intervention on weekends would be more feasible. Indeed, workers tend to extend their sleep duration on weekends to compensate for sleep debt accumulated between Monday-Friday (7).

A potential problem with attempting to sleep longer on weekends involves circadian rhythms. Specifically, delayed wake-up times on weekends have undesirable effects on alertness and performance during the subsequent weekdays (eg, the Blue Monday phenomenon) $(16,17)$. These disadvantages need to be avoided, even if a certain amount of weekend sleep (ie, sleep compensation) would be important to facilitate recovery from work-induced fatigue. Currently, little is known about which factors (ie, sleep extension or sleep regularity) should be prioritized for promoting fatigue recovery. Given that daytime workers are likely to compensate for

1 National Institute of Occupational Safety and Health, Kawasaki, Japan.

2 Department of Management Design, Faculty of Business Administration, Osaka International University, Osaka, Japan.

Correspondence to: Tomohide Kubo, PhD, National Institute of Occupational Safety and Health, 6-21-1, Nagao, Tama-ku, Kawasaki 2148585, Japan. [E-mail: kubo@h.jniosh.go.jp] 
the sleep debt they accumulate throughout the week by extending their weekend sleep times at the expense of sleep regularity (7), examining the costs and benefits of extended sleep duration during weekends is crucial in terms of occupational health. Unfortunately, to the best of our knowledge, no research has examined the effects of sleep extension during weekends among workers. The present study was conducted to determine whether sleep extension during weekends improves alertness and performance during the subsequent weekdays for workers with habitually short sleep times.

\section{Methods}

\section{Participants}

Before the study began, a questionnaire was distributed to 402 employees working at an electric company in Kyoto prefecture in order to select possible participants. The respondents were given the morningness-eveningness questionnaire (18) and asked about their habitual sleep time during weekdays and weekends and their health condition (ie, whether they have been sick and whether they take or have taken prescription medications). The selection criteria for participants were set as (i) "neither entirely morning nor evening type," as evaluated by the questionnaire, (ii) $<6$ hours mean sleep duration on weekdays, and (iii) taking no prescription medications. Consequently, 49 respondents who met the selection criteria were recruited. Of these, 28 employees [mean 38.8, standard deviation (SD) 8.5 years old, 18 men and 10 women] who were able to attend all sessions of the study were selected as participants. However, two participants withdrew from the study, citing job requirements and unexpectedly poor health conditions, respectively (mean 38.3, SD 8.1 years old, 18 men and 8 women). Regarding their social status, 23 participants cohabited with someone, whereas 2 participants lived alone (1 participant did not answer). Additionally, their weekly working hours in the past month were 35-40 hours for $34.6 \%(\mathrm{~N}=9), 41-50$ for $42.3 \%(\mathrm{~N}=11), 51-60$ for $19.2 \%(\mathrm{~N}=5)$, and $61-70$ for $3.8 \%(\mathrm{~N}=1)$. Before the study began, the participants were provided with an information sheet outlining the goals of the study and were given the opportunity to ask questions. The Research Ethics Committee of the National Institute of Occupational Safety and Health, Japan, approved this study. All participants gave written informed consent and received payment for their participation.

\section{Study design}

This study lasted three successive weeks (from Monday of the first week to Thursday of the third week; see figure 1). The participants were required to complete two conditions (the intervention and the habitual weekend sleep condition). Half the participants underwent the conditions in one order (eg, from the intervention to the habitual weekend sleep condition) and the other half underwent the conditions in the reverse. They were instructed to stay in bed for $\geq 8$ hours between 22:00-09:00 hours on the weekend (Friday, Saturday, and Sunday) of the first week as a sleep intervention and to keep their habitual sleep-wake patterns as a control beginning the weekend of the second week through Thursday of the third week.

\section{Measurements}

A battery of tests, which consisted of a psychomotor vigilance task, self-rated fatigue symptoms, and blood pressure, was used to measure the effects of the study conditions.

The psychomotor vigilance task is a sustainedattention reaction time task with a random interstimulus interval of 2-10 seconds (PVT-192, Ambulatory Monitoring, Ardsley, New York, USA) (19). Lapses (reaction times $>500$ milliseconds) were counted during each 10-minute test as a measure of performance impairment indicative of reduced behavioral alertness. The data were analyzed for speed (1/reaction time $\times$ 1000) and transformed lapses (square root transform [SQR(lapses)+SQR(lapses+1)]).

Subjective fatigue symptoms were assessed by a questionnaire that asked about work-related feelings of fatigue Jikaku-sho shirabe (20), which was proposed by the Industrial Fatigue Research Committee of Japanese Occupational Health in 2002. This questionnaire consists of 25 subjective fatigue symptoms that are categorized into 5 factors of feeling: (i) drowsiness, (ii) instability, (iii) uneasiness, (iv) local pain or dullness, and (v) eyestrain. For each item, participants are requested to estimate the intensity of their feelings using the following scale: "totally disagree," "agree scarcely," "agree slightly," "agree considerably," and "agree strongly." These five intensities were assigned scores of 1-5 points, respectively.

The participants' blood pressure (ES-P2100, TERUMO Corporation, Tokyo, Japan) was measured twice during each test. The mean of these measurements was recorded.

Sleep was monitored by an actigraph (Micro-mini RR, Ambulatory Monitoring, Ardsley, New York, USA) throughout the period of the study. The actigraph was secured on the participants' non-dominant wrist. Epoch length was set at 1-minute intervals. Sleep data were analyzed by Action-W® version 2.4.20 software (Ambulatory Monitoring, Ardsley, New York, USA) with the Cole-Kripke algorithm (21). In this study, total sleep time 


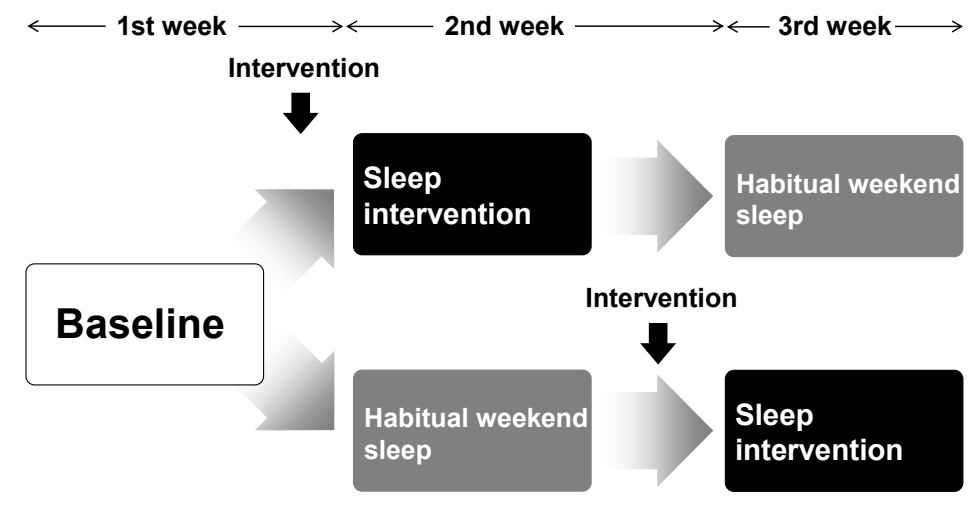

Figure 1. Study design (within-subject design). In the sleep intervention condition, participants were instructed to stay in bed for $\geq 8$ hours between 22:00-09:00 hours on weekends (Friday, Saturday, and Sunday) of the $1^{\text {st }}$ week (or $2^{\text {nd }}$ week) as a sleep intervention. Meanwhile, they were required to keep their habitual weekend sleep patterns as a control on the weekend of the $2^{\text {nd }}$ week (or $1^{\text {st }}$ week), followed until Thursday of the $3^{\text {rd }}$ week.

(TST), sleep efficiency, bedtime, and wake time were analyzed to assess the quality of sleep. Sleep efficiency was calculated as: (ratio of TST to total time in bed) $\times(100)$.

\section{Procedure}

The present study lasted three weeks. Participants were required to follow their usual sleep-wake cycles in the first week as a baseline. In the intervention condition, they were instructed to remain in bed for $\geq 8$ hours between 22:00-09:00 hours and prohibited from taking a daytime nap on weekends (Friday, Saturday, and Sunday). The participants were encouraged to spend the weekends following the instructions as closely as possible. No other assistance was provided (eg, a telephone reminder). In the habitual weekend sleep condition, participants were required to keep their habitual sleep-wake patterns on the weekend.

The test battery was conducted on Monday and Thursday during the afternoon in all three weeks. Participants were instructed to arrive at a testing room between 14:00-15:00 hours. The order of measurements was subjective fatigue ( 5 minutes), blood pressure (5 minutes), and the psychomotor vigilance task (10 minutes). During the test period, participants were required to switch off their cell phones and take off their wristwatches so that they could concentrate on the test. They also practiced the psychomotor vigilance task for a few minutes before each test period.

\section{Data analysis}

Data for the test battery and actigraph were analyzed using two-way mixed-model analysis of variance (ANOVA). The ANOVA model consisted of subjects as the random effect and the following fixed effects: condition (sleep intervention versus habitual weekend sleep) and day (test battery: 4 levels [Monday, Thursday, Monday, Thursday] and actigraph: 7 levels [Monday, Tuesday, Wednesday, Thursday, Friday, Saturday, Sun- day]). The main interest was in the interaction effect. Significant interaction was assessed using post-hoc t-tests to reveal whether there was a significant difference between conditions. All statistical analyses were performed using SPSS 17.0 for Windows (SPSS Inc, Chicago, IL, USA).

\section{Results}

The results of mixed-model ANOVA for all measurements are presented in table 1 .

\section{Sleep}

For sleep parameters, significant interactions were observed in TST and bedtime (F6,325=9.74, $\mathrm{P}<0.001$ and $\mathrm{F} 6,325=17.21, \mathrm{P}<0.001$, respectively; figure 2). Post-hoc analyses showed that weekend sleep patterns were significantly longer in TST and participants had earlier bedtimes in the intervention than the habitual weekend sleep condition (all $\mathrm{P}<0.05$ ). However, no significant interaction was observed between sleep efficiency and wake time. Regarding the main effect of condition, significant differences were observed in TST ( $\mathrm{F} 1,325=44.56, \mathrm{P}<0.001)$, bedtime $(\mathrm{F} 1,325=50.47$, $\mathrm{P}<0.001)$, and wake time ( $\mathrm{F} 1,325=5.84, \mathrm{P}=0.016)$, but not sleep efficiency. The main effect of day was significant for TST $(\mathrm{F} 6,325=23.64, \mathrm{P}<0.001)$, sleep efficiency $(\mathrm{F} 6,325=2.93, \mathrm{P}<0.001)$, bedtime $(\mathrm{F} 6,325=8.10$, $\mathrm{P}<0.001)$, and wake time $(\mathrm{F} 6,325=51.62, \mathrm{P}<0.001)$.

\section{Sustained attention}

Psychomotor vigilance task performance showed significant interactions in reaction times and lapses (F3,175=6.01, $\mathrm{P}=0.001$ and $\mathrm{F} 3,175=4.53, \mathrm{P}=0.004$, respectively; figure 3$)$. Significantly shorter reaction times $(\mathrm{P}<0.05)$ and fewer lapses $(\mathrm{P}<0.05)$ were observed 
Table 1. Mixed-model analysis of variance results.

\begin{tabular}{|c|c|c|c|c|c|c|}
\hline \multirow[b]{4}{*}{ Actigraphic sleep parameters a } & \multicolumn{6}{|c|}{ Mixed-model analysis of variance } \\
\hline & \multicolumn{2}{|c|}{ Condition } & \multicolumn{2}{|c|}{ Day } & \multicolumn{2}{|c|}{ Interaction } \\
\hline & F-value & P-value & F-value & P-value & F-value & P-value \\
\hline & & & & & & \\
\hline Total sleep time & 44.56 & 0.000 & 23.64 & 0.000 & 9.74 & 0.000 \\
\hline Sleep efficiency & 0.82 & 0.367 & 2.93 & 0.008 & 1.97 & 0.069 \\
\hline Bedtime & 50.47 & 0.000 & 8.10 & 0.000 & 17.21 & 0.000 \\
\hline Wake time & 5.84 & 0.016 & 51.62 & 0.000 & 1.39 & 0.219 \\
\hline \multicolumn{7}{|l|}{ Psychomotor vigilance task ${ }^{b}$} \\
\hline Reaction time & 0.02 & 0.890 & 0.41 & 0.745 & 6.01 & 0.001 \\
\hline Lapse & 0.06 & 0.803 & 0.62 & 0.606 & 4.53 & 0.004 \\
\hline \multicolumn{7}{|l|}{ Subjective fatigue questionnaire ${ }^{\mathrm{b}}$} \\
\hline Drowsiness & 2.90 & 0.090 & 4.29 & 0.006 & 1.81 & 0.148 \\
\hline Eyestrain & 0.18 & 0.670 & 6.14 & 0.001 & 0.34 & 0.794 \\
\hline Instability & 0.09 & 0.759 & 11.54 & 0.000 & 0.18 & 0.910 \\
\hline Uneasiness & 0.24 & 0.627 & 7.84 & 0.000 & 0.08 & 0.971 \\
\hline Local pain or dullness & 0.00 & 0.988 & 2.44 & 0.066 & 0.02 & 0.995 \\
\hline \multicolumn{7}{|l|}{ Blood pressure ${ }^{b}$} \\
\hline Systolic blood pressure & 1.21 & 0.274 & 13.62 & 0.000 & 1.69 & 0.171 \\
\hline Diastolic blood pressure & 0.01 & 0.906 & 2.38 & 0.071 & 0.24 & 0.869 \\
\hline
\end{tabular}

a Condition $=\mathrm{df}(1,325)$; Day and Interaction $=\mathrm{df}(6,325)$.

${ }^{\mathrm{b}}$ Condition $=\mathrm{df}(1,175)$; Day and Interaction $=\mathrm{df}(3,175)$.

on Mondays following the intervention condition, as compared with the habitual weekend sleep condition. In contrast, the intervention condition showed significantly longer reaction times and a larger number of lapses on Thursdays than the habitual weekend sleep condition $(\mathrm{P}<0.05)$. No significant main effects of condition and day were observed.

\section{Subjective fatigue}

No significant interactions were found between the intervention and the habitual weekend sleep condition in any of the five subscales of the questionnaire for workrelated feelings of fatigue (figure 4). No significant main effects of condition were observed for any of the five subscales. However, the main effects of day were significant for drowsiness $(\mathrm{F} 3,175=4.29, \mathrm{P}<0.001)$, eyestrain $(\mathrm{F} 3,175=6.14, \mathrm{P}=0.001)$, instability $(\mathrm{F} 3,175=11.54$, $\mathrm{P}<0.001$ ), and uneasiness ( $\mathrm{F} 3,175=7.84, \mathrm{P}<0.001)$, but not for local pain or dullness.

\section{Blood pressure}

The two parameters of blood pressure showed no significant interactions between the intervention and the habitual weekend sleep condition (figure 5). No main effects of condition were found for the two parameters. The main effects of day were significant for systolic blood pressure $(\mathrm{F} 3,175=13.62, \mathrm{P}<0.001)$, but not for diastolic blood pressure.

\section{Discussion}

The purpose of this study was to examine whether weekend sleep extension contributes to improved alertness and performance during the following week among daytime workers with habitually short sleep duration. TST for the intervention condition was 1-2 hours longer per day than for the habitual weekend sleep condition (from 5-7 hours). However, TST during weekdays after the intervention again returned to 5 hours. Performance on the psychomotor vigilance task significantly improved on Monday after the intervention. Nevertheless, significantly longer reaction times and a larger number of lapses on the psychomotor vigilance task were observed on Thursday after the intervention than after the habitual weekend sleep condition. With respect to subjective fatigue and blood pressure, significant favorable effects of sleep extension were not found. Taken together, the present findings suggest that sleep extension on weekends produced favorable influences on alertness and performance during the first day of the subsequent week, though these benefits dissipated after that.

As expected, an improvement in alertness and performance was observed on the Monday following the sleep intervention. This finding agrees with previous studies, which reported better neurobehavioral performance and less subjective sleepiness by recovery sleep following shortened sleep protocols (22-24). However, these findings were inconsistent with the findings of 


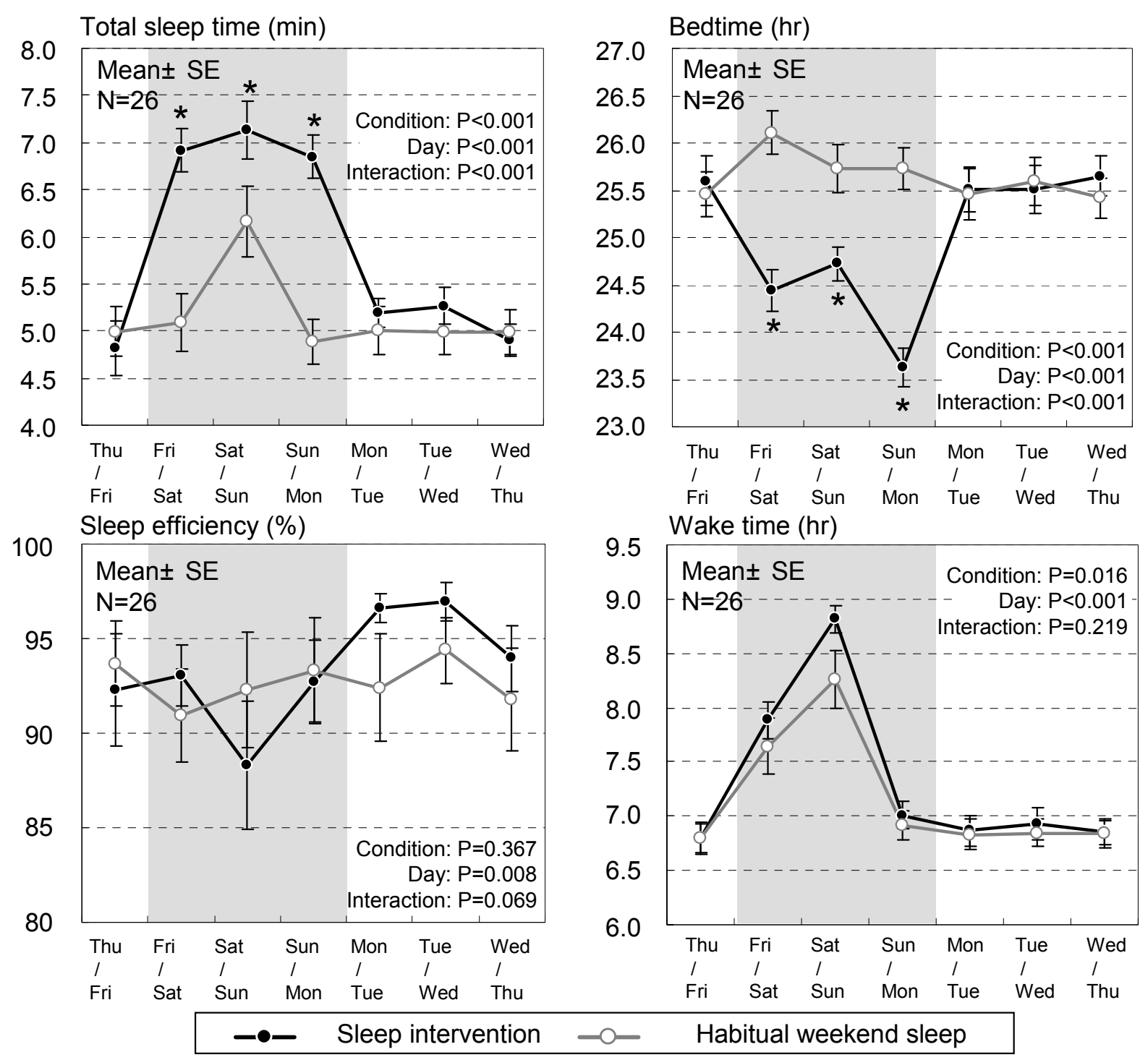

Figure 2. Mean and standard error (SE) of actigraphic sleep parameters before, during and after sleep intervention. Shared area indicates the period of the sleep intervention. * Significant difference from control condition at $\mathrm{P}<0.05$.

Taylor et al (16). The study reported that a 2-hour delay in wake-up time on the weekend deteriorated alertness and performance until the middle of the next week. One explanation for this discrepancy is that the participants in the present study were habitually sleep deprived, whereas normal sleepers (those who sleep approximately 8 hours) participated in the previous study. Hence, the effects of sleep extension might have worked to cancel potential sleep debt that participants of the present study had been accumulating. In the previous study (16), extended nighttime sleep (mean 9.8 hours) might act as "extra" sleep. Sleep extension is shown to result in less clear improvements in alertness and performance for individuals without sleep debt $(23,25,26)$. Another contributing factor may be wake time. The participants in the present study woke up by 09.00 hours at the latest (figure 2), whereas those in Taylor et al's study awoke at approximately 10:30 hours. Earlier wake time may prevent circadian phase delay, causing negative influences on daytime function on subsequent weekdays.

An important question in the present study is how long the benefit of weekend sleep extension lasted following the subsequent Monday. It was unexpected that a significantly longer reaction time and a larger number of lapses on the psychomotor vigilance task were found on the Thursday after the intervention than after the habitual weekend sleep condition (figure 3). This finding might be related to the immediate return of sleep 

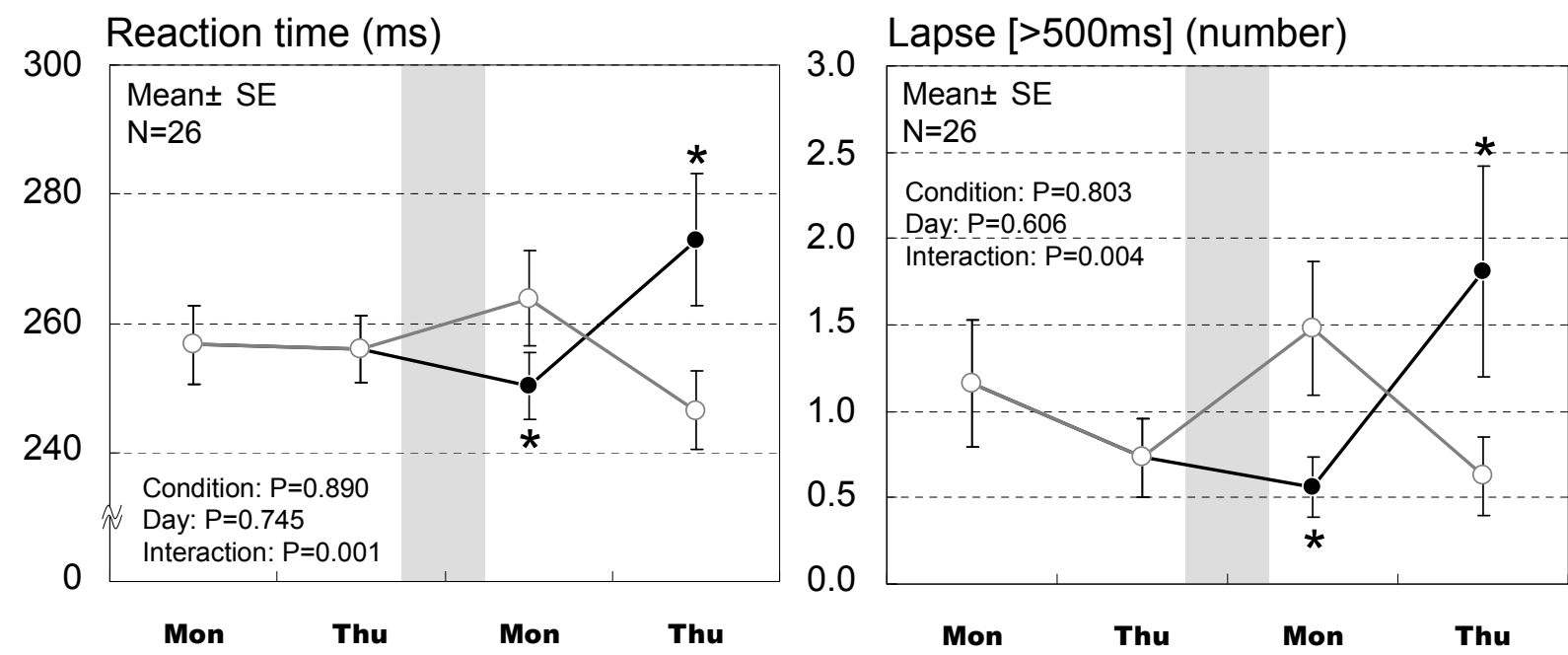

\section{-•- Sleep intervention $-\mathrm{O}-\quad$ Habitual weekend sleep}

Figure 3. Mean and standard error (SE) of psychomotor vigilance task for reaction times and lapses before and after the sleep intervention. Shared area indicates the period of the sleep intervention. ${ }^{*}$ Significant difference from control condition at $\mathrm{P}<0.05$.

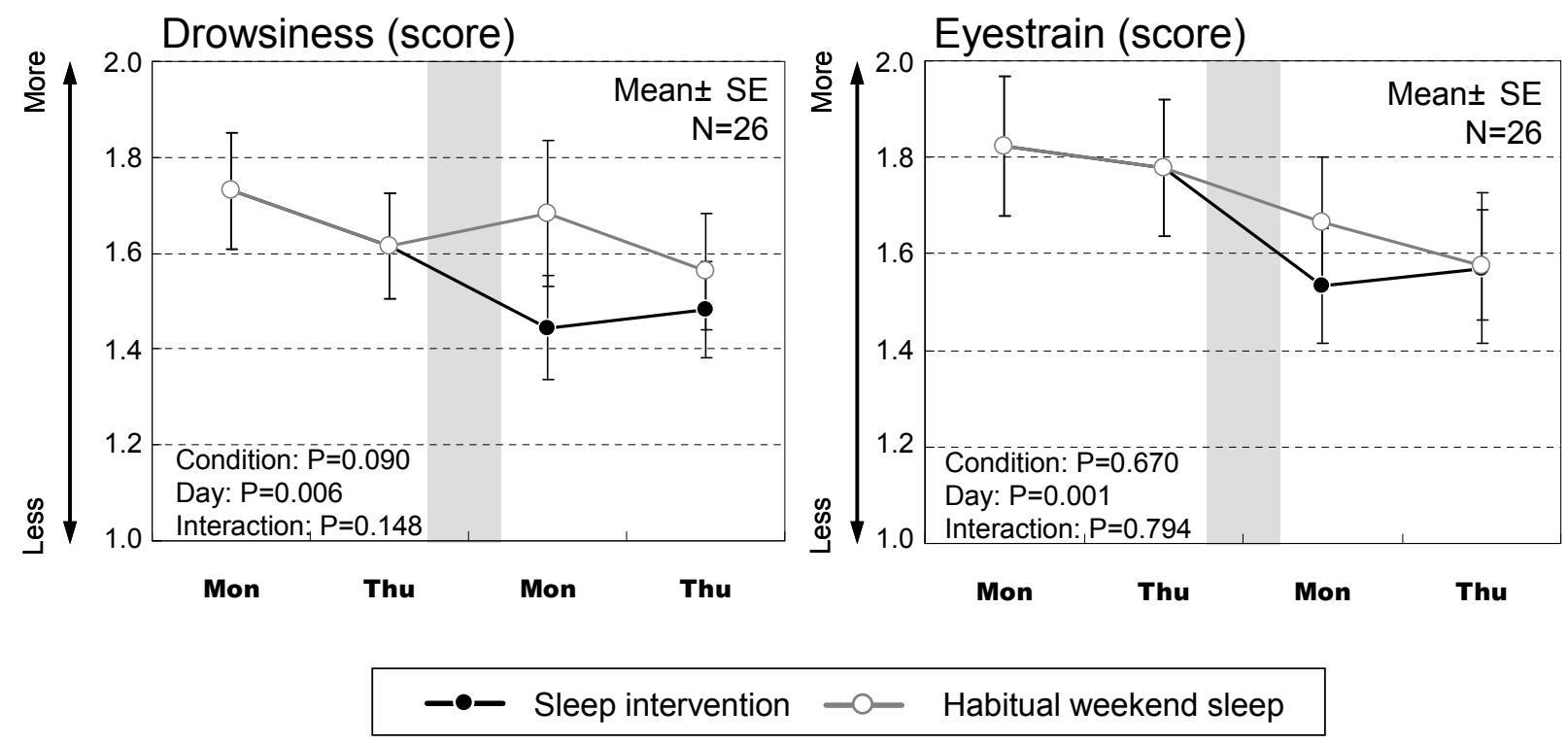

Figure 4. Mean and standard error (SE) of subjective fatigue questionnaire for drowsiness and eyestrain before and after the sleep intervention. Shared area indicates the period of the sleep intervention. 

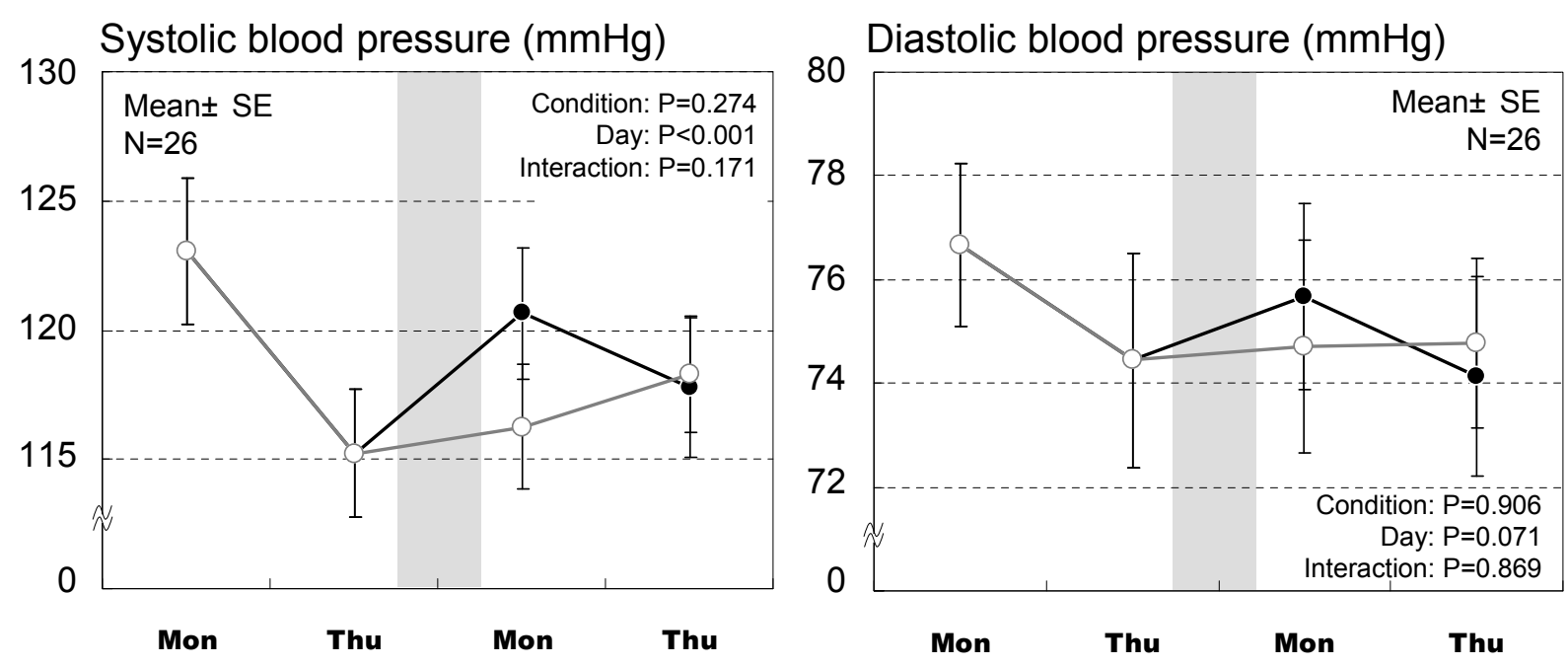

\section{-•- Sleep intervention $-\mathrm{O}-$ Habitual weekend sleep}

Figure 5. Mean and standard error (SE) of blood pressure before and after the sleep intervention. Shared area indicates the period of the sleep intervention.

duration following the intervention (from 7 to 5 hours). In the present study, sleep duration on the weekends was approximately 2 hours longer per day for the intervention than the habitual weekend sleep condition (figure 2). However, sleep duration on weekdays after the intervention returned to 5 hours. Thus, we assume that the immediate return from the longer weekend sleep duration to the shorter weekday sleep duration may cause impaired neurobehavioral performance in the intervention condition. Additionally, given that the cumulative effects of mild sleep restriction became evident within a few days after the start of the restriction $(23,24,27)$, the favorable influences of sleep extension in this study may be cancelled due to cumulative effects.

However, a recent study indicated that one week of sleep extension not only improved performance and alertness during the subsequent period of sleep restriction but also facilitated recovery in the post-restriction period (22). These findings were inconsistent with the impairments of neurobehavioral performance on the Thursday after the intervention. In the previous research, the targeted participants were normal sleepers, but in the present research, short sleepers. Namely, the effects of sleep extension in this study might work as compensation for accumulated sleep debt among short sleepers. In contrast, one week of extended sleep times might result in the benefits of sleep extension for normal sleepers. When sleep duration is adequate not only on weekends but also weekdays, the effects of sleep extension can be maintained.
Furthermore, several possibilities exist regarding why the impaired neurobehavioral performance occurred on Thursday after the intervention. Responses to the intervention condition varied among the participants. In short, the standard deviation of reaction times and lapses was 2 or 3 times larger on Thursday after the intervention than on Monday after the intervention (SD for Monday and Thursday varied from 26.1-52.1 in reaction times and $0.9-3.1$ in lapses). Therefore, some of the workers showed greater decreases in the performance of a reaction time task toward Thursday, suggesting inter-individual differences in response to a manipulated sleep-wake pattern $(28,29)$. On the contrary, the performance data in the habitual weekend sleep condition indicate that deteriorated performance on the subsequent Monday was restored to the baseline level on Thursday. Consequently, the combined effects of these two factors are likely to lead to the current result of impaired neurobehavioral performance on Thursday after the intervention. Alternatively, the workload intensity would be unexpectedly changed on Thursday after the intervention. Another reason might be that a type-1 error because the sample size in this study was not large. Taken together, three days (Friday to Sunday) of sleep extension on weekends may have sustained the benefits for only a few days following the intervention, as far as sufficient sleep duration on the subsequent weekdays could be not ensured.

This study had some limitations. First, participants in the present study slept $<6$ hours on weekdays, despite the fact that they did not work extremely long hours 
(about $80 \%$ of workers in this study had mean weekly working hours of $<50$ hours). It is possible that they voluntarily curtailed their sleep duration. We interviewed some of the participants about the causes of their habitually short sleep times, but no clear responses emerged. In addition, the participating workers might be categorized as individuals with behaviorally induced insufficient sleep syndrome. Such a possibility, however, would be quite low, given the clinical presentation and the diagnostic criteria for this syndrome (30).

Second, it remains unclear whether the weekend sleep extension had positive effects on work productivity because the participants' work output was not evaluated.

Third, we did not measure how participants spent their leisure time. Recently, a great deal of research has been conducted on the importance of leisure activity in fatigue recovery (31-33). Moreover, findings from recent studies indicate that increased control of working time and/or days off plays a crucial role in improving workers' health (34). Therefore, the benefits of weekend sleep extension are likely to vary depending on the types of leisure activity in which the participants engage (eg, active or passive leisure) and/or working style.

Fourth, the measurements in this study could have been more optimal through the selection of different parameters, such as a circadian phase marker (eg, melatonin). Besides, increased frequency of testing, rather than only on Monday and Thursday, might further clarify the possible effects of the intervention. Furthermore, since sleep data in this study were measured by actigraphy instead of polysomnography, sleep might have been overestimated (35). Thus, it is possible that sleep extension on weekends was $<2$ hours per day.

Fifth, the present study did not address the long-term effects of sleep extension on weekends, and it remains unclear what they would be. But we speculate that the weekend sleep extension may yield favorable effects only on a few days of the following week because sleep duration on weekdays would be short, even if the intervention were repeated for a long period. Both organizational and individual efforts should thus be directed to ensuring sufficient duration of sleep not only on the weekends but also on weekdays.

Finally, it may be difficult to continue the weekend sleep intervention over a long period, given the present data showing an immediate return to short sleep following the weekends. We believe that the participants' high compliance was achieved because of the single shortterm (2-3 days) intervention that spanned a weekend.

The sleep intervention in this study succeeded in lengthening the sleep duration of workers with habitually short sleep periods. Longer weekend sleep resulted in acute improvements of alertness and performance, but the improvements were not present later during the workweek. However, the benefits of weekend sleep extension might be maintained if the participants receive sufficient sleep during the post-intervention week. Our present findings suggest the significance of vouchsafing adequate sleep nightly for optimal levels of worker safety and health.

\section{Acknowledgement}

The study was supported by a Grant-in-Aid from the National Institute of Occupational Safety and Health, Japan (P18-01, P22-01).

\section{References}

1 OECD. Employment outlook [Internet]. Paris: OECD. 2008. [Cited 28 July 2010.] Available from: http://wwwoecdorg/ dataoecd/54/57/40846335.pdf.

2 Åkerstedt T, Fredlund P, Gillberg M, Jansson B. Work load and work hours in relation to disturbed sleep and fatigue in a large representative sample. J Psychosom Res. 2002;53:585-8. doi:10.1016/S0022-3999(02)00447-6.

3 Iwasaki K, Takahashi M, Nakata A. Health problems due to long working hours in Japan: working hours, workers' compensation (Karoshi), and preventive measures. Ind Health. 2006;44:537-40. doi:10.2486/indhealth.44.537.

4 Kleppa E, Sanne B, Tell GS. Working overtime is associated with anxiety and depression: the Hordaland Health Study. J Occup Environ Med. 2008;50:658-66. doi:10.1097/ JOM.0b013e3181734330.

5 Nakashima M, Morikawa Y, Sakurai M, Nakamura K, Miura $\mathrm{K}$, Ishizaki M, et al. Association between long working hours and sleep problems in white-collar workers. J Sleep Res. 2011 Mar;20(1):110-6. doi:10.1111/j.1365-2869.2010.00852.x.

6 Suwazono Y, Nagashima S, Okubo Y, Uetani M, Kobayashi E, Kido T, et al. Estimation of the number of working hours critical for the development of mental and physical fatigue symptoms in Japanese male workers - application of benchmark dose method. Am J Ind Med. 2007;50:173-82. doi:10.1002/ajim.20432.

7 Japan Ministry of Internal Affairs and Communications Summary of results of the 2006 survey on time use and leisure activities [Internet]. Tokyo: Japan Ministry of Internal Affairs and Communications;2006. [Cited 13 October 2010.] Available from: http://www.stat.go.jp/english/data/ shakai/2006/pdf/jikan-a.pdf.

8 Åkerstedt T, Nilsson PM, Kecklund G. Sleep and recovery. In: Sonnentag S, Perrewe PL, Ganster DC, editors. Current perspectives on job-stress recovery. Bingley, UK: JAI Press; 2009. p205-47.

9 Dahlgren A, Kecklund G, Åkerstedt T. Overtime work and 
its effects on sleep, sleepiness, cortisol and blood pressure in an experimental field study. Scand J Work Environ Health. 2006;32:318-27.

10 Härmä M. Work hours in relation to work stress, recovery and health [review]. Scand J Work Environ Health. 2006;32:502-14.

11 Tucker P, Brown M, Dahlgren A, Davies G, Ebden P, Folkard $S$, et al. The impact of junior doctors' worktime arrangements on their fatigue and well-being. Scand J Work Environ Health. 2010;36:458-65. doi:10.5271/sjweh.2985.

12 Beckers DG, van Hooff ML, van der Linden D, Kompier MA Taris TW, Geurts SA. A diary study to open up the black box of overtime work among university faculty members. Scand J Work Environ Health. 2008;34:213-23

13 van der Hulst M. Long work hours and health [review]. Scand J Work Environ Health. 2003;29:171-88.

14 Virtanen M, Ferrie JE, Gimeno D, Vahtera J, Elovainio M, Singh-Manoux A, et al. Long working hours and sleep disturbances: the Whitehall II prospective cohort study. Sleep. 2009;32:737-45.

15 Virtanen M, Singh-Manoux A, Ferrie JE, Gimeno D, Marmot MG, Elovainio M, et al. Long working hours and cognitive function: the Whitehall II Study. Am J Epidemiol. 2009;169:596-605. doi:10.1093/aje/kwn382.

16 Taylor A, Wright H, Lack L. Sleeping-in on the weekend delays circadian phase and increases sleepiness the following week. Sleep and Biological Rhythms. 2008;6:172-9. doi:10.1111/j.1479-8425.2008.00356.x.

17 Yang CM, Spielman AJ, D'Ambrosio P, Serizawa S, Nunes J, Birnbaum J. A single dose of melatonin prevents the phase delay associated with a delayed weekend sleep pattern. Sleep. 2001;24:272-81.

18 Horne JA, Östberg O. A self-assessment questionnaire to determine morningness-eveningness in human circadian rhythms. Int J Chronobiol. 1976;4:97-110.

19 Dinges D, Powell J. Microcomputer analyses of performance on a portable simple visual RT task during sustained operations. Behavior research methods, instruments, \& computers. 1985;17:652-5. doi:10.3758/BF03200977.

20 Kubo T, Tachi N, Takeyama H, Ebara T, Inoue T, Takanishi $\mathrm{T}$, et al. Characteristic patterns of fatigue feelings on four simulated consecutive night shifts by "Jikaku-sho shirabe." Sangyo Eiseigaku Zasshi. 2008;50:133-44.

21 Cole RJ, Kripke DF, Gruen W, Mullaney DJ, Gillin JC. Automatic sleep/wake identification from wrist activity. Sleep 1992;15:461-69.

22 Rupp TL, Wesensten NJ, Bliese PD, Balkin TJ. Banking sleep: realization of benefits during subsequent sleep restriction and recovery. Sleep. 2009;32:311-21.

23 Belenky G, Wesensten NJ, Thorne DR, Thomas ML, Sing HC, Redmond DP, et al. Patterns of performance degradation and restoration during sleep restriction and subsequent recovery: a sleep dose-response study. J Sleep Res. 2003;12:1-12. doi:10.1046/j.1365-2869.2003.00337.x.
24 Axelsson J, Kecklund G, Åkerstedt T, Donofrio P, Lekander $\mathrm{M}$, Ingre M. Sleepiness and performance in response to repeated sleep restriction and subsequent recovery during semi-laboratory conditions. Chronobiol Int. 2008;25:297-308. doi:10.1080/07420520802107031.

25 Harrison Y, Horne JA. Long-term extension to sleep - are we really chronically sleep deprived? Psychophysiology 1996;33:22-30. doi:10.1111/j.1469-8986.1996.tb02105.x.

26 Horne J, Anderson C, Platten C. Sleep extension versus nap or coffee, within the context of 'sleep debt.' J Sleep Res. 2008;17:432-6. doi:10.1111/j.1365-2869.2008.00680.x.

27 Van Dongen HP, Maislin G, Mullington JM, Dinges DF. The cumulative cost of additional wakefulness: dose-response effects on neurobehavioral functions and sleep physiology from chronic sleep restriction and total sleep deprivation. Sleep. 2003;26:117-26.

28 Van Dongen HP, Baynard MD, Maislin G, Dinges DF. Systematic interindividual differences in neurobehavioral impairment from sleep loss: evidence of trait-like differential vulnerability. Sleep. 2004;27:423-33.

29 Kubo T, Takahashi M, Tachi N, Takeyama H, Ebara T, Inoue $\mathrm{T}$, et al. Characterizing recovery of sleep after four successive night shifts. Ind Health. 2009;47:527-32. doi:10.2486/ indhealth.47.527.

30 American Academy of Sleep Medicine. Behaviorally induced insufficient sleep syndrome. In: International classification of sleep disorders. Diagnostic and coding manual, 2nd ed. Westchester, IL: American Academy of Sleep Medicine; 2005. p104-6.

31 Sonnentag S, Jelden S. Job stressors and the pursuit of sport activities: A day-level perspective. J Occup Health Psychol. 2009;14:165-81. doi:10.1037/a0014953.

32 Tucker P, Dahlgren A, Akerstedt T, Waterhouse J. The impact of free-time activities on sleep, recovery, and well-being. Appl Ergon. 2008;39:653-62. doi:10.1016/j.apergo.2007.12.002.

33 Winwood P, Bakker A, Winefield A. An investigation of the role of non-work-time behavior in buffering the effects of work strain. J Occup Environ Med. 2007;49:862. doi:10.1097/ JOM.0b013e318124a8dc.

34 Takahashi M, Iwasaki K, Sasaki T, Kubo T, Mori I, Otsuka Y. Worktime control-dependent reductions in fatigue, sleep problems, and depression. Appl Ergon. 2011;42:244-50. doi:10.1016/j.apergo.2010.06.006.

35 Ancoli-Israel S, Cole R, Alessi C, Chambers M, Moorcroft W, Pollak CP. The role of actigraphy in the study of sleep and circadian rhythms. Sleep. 2003;26:342-92.

Received for publication: 15 October 2010 